Roberta I. Shaffer

\title{
BRINGING THINGS TO THE CENTER: THE CENTER FOR THE CULTURAL RECORD OF THE GRADUATE SCHOOL OF LIBRARY AND INFORMATION SCIENCE AT THE UNIVERSITY OF TEXAS AT AUSTIN
}

Editor's note: This essay is based in great part on a lecture given by David B. Gracy, director of the Center for the Cultural Record, at the June 2000 Annual Conference of the American Library Association. Roberta Shaffer, however, is entirely responsible for its presentation in this article.

DESPITE THE DEATH THREATS against schools of library and information science (LIS) that were rampant during the final decades of the twentieth century, LIS graduate programs are alive and well and have a promising prognosis for the twenty-first century. The challenge, however, is to adapt to the changing personae of the American university and the emerging roles of information professionals in all aspects of our society.

Today's university is less concerned with maintaining the strict boundaries of traditional disciplines and instead encourages thinking that is transdisciplinary. Although this new model respects the uniqueness of various subject areas, it celebrates collaboration and interdisciplinary research and teaching.

Information professionals are no longer tied to place. They now may define themselves in terms of knowledge creation, access, and preservation. Indeed, they have become critical teammates in a knowledge-based society. This society, however, is not bound to buildings or institutions. We are moving away from a definition of our profession based on where we work. 
Therefore, LIS schools are seeking to create intelligent alliances akin to strategic alliances in the marketplace. Many have even adapted the concept of "branding" to the academy. In this setting, "branding" really means identification of one's strengths and ways to promote and maximize them.

The marketing concept of "branding" burst on the media scene in the early 1990s. It was becoming clear that the information age of the last twentyfive years of the twentieth century would give rise to the idea age of the twenty-first century. Entities of all kinds - commercial, cultural, educational, and social-began to realize that in the future viability would not rest simply with those that did what they did best but, rather, with those that were the only ones that did what they did. To survive (and not just surpass competition as had been the old model based on price/cost and quality), an entity needed to have a unique "branding."

Some factors that led to the almost immediate and universal acceptance of "branding" were: the irrelevance of traditional geographic boundaries; the expectation of immediate service on a 24/7 basis; the globalization of trade and mechanisms of delivery; and the general impact of technologies such as wireless communication and the Internet. In the educational sector, the emergence of distance education or distributed learning was another key factor.

It was with this in mind that the Graduate School of Library and Information Science (GSLIS) at the University of Texas-Austin (UT-Austin) launched its first specialized center in June 2000, the Center for the Cultural Record.

\section{Why, Why Now, and Why UT at Austin?}

The answer to this question involves several concomitant factors that came together over the past few years. For several years, we have had a stellar program in Archives and Records Enterprise. At the same time, the Preservation and Conservation Studies program that we had taken over from Columbia 
University was nearing its first decade as a "Texas" program and was no longer thought of as "Columbia II." Further during this period, there had been enough turnover in teaching staff and shift in philosophy to put a "Lone Star" stamp on preservation and conservation studies. In addition, the program's highly respected advisory board had taken an active part in ensuring that the program would remain relevant and organic over time. Finally, increasing attention was being paid in Texas to museums of both the traditional variety, with worldclass architectural design and masterpiece collections, and the popular variety, which includes community-based museums. The latter are often credited with the boom in virtual museums across the museum spectrum. The ease of creating Web sites has enabled many communities with scattered members to bring together cultural artifacts along with stories about traditions and leaders and to keep languages alive among younger, assimilating generations. Moreover, there is ample opportunity to make such Web sites interesting and compelling to Web-based museum-goers who are not part of the community per se.

In its most basic form, the Center for the Cultural Record (CCR) is a joining of three siblings: the Archival and Records Enterprise Program; Preservation and Conservation Studies; and Museum Studies. The connections between and among these siblings foster exploration of the concepts, contexts, and components of the cultural record of human civilization. We realized that there was a growing convergence of interests among archives, libraries, and museums. Their missions overlapped in areas of collection, preservation and conservation, and dissemination. In addition, each played a critical role in the cultural record of society. Moreover, all three face similar challenges in the adaptation of technology, the reliance on government funding and support, and the maintenance of social credibility and relevance.

Although the GSLIS did not have a formal program in museum studies, our faculty had taken a scholarly and service interest in museums as information centers. Over the years, many students pursued careers in museums using their GSLIS education, supplemented by courses offered elsewhere within the university. 
The CCR provides a platform for students and scholars to examine both information and objects in any and all media. Particular emphasis is placed on the media that carry information, how the medium shapes the message, and how our knowledge and understanding of the message is enhanced or diminished by the particular medium and the nature of the document itself. The CCR also builds on an acknowledgment of the connections between museums and libraries, which is evidenced by the recent creation at the federal level of the Institute of Museum and Library Studies. Finally, our orientation is on the museum as an educational experience and a knowledge resource. Hence the emphasis may be more on the "virtual" than on the physical. The relationship of the museum to the archive and the library is in "seeing" information objects and in casting, interpreting, and enlivening them.

As a center with an academic purpose, the CCR presents some valuable and unique attributes by its placement at a major research university and its location in the heart of Texas. The advantage of being at a major university is the ability to draw on internationally recognized scholarship across a variety of disciplines. Another advantage is that of having access to a major research library and number of specialized research collections (The Benson Latin American Collection, The Center for American History, The Harry Ransom Humanities Research Center, and the Tarlton Law Library, to name the largest ones). Currently, plans are under way to build a brand-new university museum (the Blanton Art Museum) and to renovate the Ransom Center. The benefit of being within eyeshot of the capital of Texas also is noteworthy in providing students and scholars applied opportunities to work with materials and assist in the creation of policies and procedures.

The state itself provides other assets. Among these are: a strong and diversified economy; recognition of the key role that the cultural record plays in developing responsible (informed) citizens; a population that represents a wealth of ethnic backgrounds and traditions; pride in the rich history and lore of Texas; and the realization that workforce demand and population growth trends are shifting to the South and Southwest regions of the coun- 
try. In addition, the new Texas State History Museum, which is scheduled to open in Austin in the spring of 2001, is located just across the street from the GSLIS.

Austin has developed a personality that is more than just a capital city and home to a very large university (50,000-plus students on one campus). The Center for the Cultural Record finds itself sharing a city address with the LBJ Presidential Library, the National Archives of the Episcopal Church, the Daniel Center for Legal History at the State Bar, the Austin History Center, and the Dell Children's Museum. As home to many leading hi-tech companies, Austin is recognized as one of the seven top "technopolis" cities in the United States.

We have every confidence that Austin will prove to be a good neighbor in support of the CCR. It will surely expose students to a variety of practices and cutting-edge technology. In addition, we will look to Austin-based businesses and government for financial support as well as expertise. For its part, the CCR believes that it will be a good public citizen in undertaking its commitment to look for solutions to pressing problems and to address real-world issues.

\section{Building the Foundation}

The CCR is administratively contained within the Graduate School of Library and Information Science. This school, like many of its peer institutions, has recently reviewed its curriculum and created a new course of study that, like the CCR, looks at contexts, contents, consumers, and connections.

It should be noted that much of the motivation for changing LIS curricula came from student pressure. At GSLIS, it was clear that students wanted the freedom to combine courses from different disciplines and subspecialties. They also wanted to fully comprehend the implications of new technologies and formats such as digitization. 
The new GSLIS curriculum moves away from a track or specialization model to one that is designed to foster more exchange between students and faculty and to find the common ground(s) facing information professionals. In the past, we tended, by mere curriculum design, to segregate studies early in the student's career and to provide little opportunity for cross-pollination.

The impact of this new curricular philosophy will mean that students will have more required courses. The faculty will need to take a more generalized approach to classroom lectures and readings. Student assignments will need to be flexible to enable the individual either to take a specialized approach to the assignment or a more general one. And, everything we do will need to consider the opportunity for greater interaction. This includes not only our courses, but also how we allocate our physical space, the kinds of colloquia we offer, what student organizations we have, which visiting scholars we invite, and what continuing education we promote.

It is especially important to mention a new requirement: students will choose either to pursue a "capstone experience" or to write a master's thesis as they near the end of their degree. This is the student's chance to bring it all together. The capstone will require a professional-level placement within an organization, in which the student will provide significant (tangible, measurable) value to the host organization and in turn receive an experience that is far richer than a traditional internship or practicum. It is our plan to engage the entire information community in our educational mission through these capstone experiences. We will call on colleagues across the country and the world to participate in the capstone by providing students with experiences.

With the new curriculum in place and the CCR established, additional LIS faculty have been recruited to enhance existing teaching and research strengths. The arrival of Patricia Galloway, formerly the chief architect of the electronic records initiative at the Mississippi Department of Archives and History, will augment electronic and digital records expertise. Galloway 
will become part of the university's museum faculty. Paul Wilson from New South Wales contributes an outstanding background in corporate, film, international, and comparative archives. Emilio Zamora, an established historian scholar in border studies provides a role model for scholarship and study in the documentation, management, and use of records within a specific community. These new faculty members join David Gracy, who is director of the Center for the Cultural Record. They also complement the existing faculty, which has traditionally represented a good balance of content and information technology expertise. Again, a wide variety of teaching faculty is available to our students because of resources on campus and the technological wealth in Austin-all of which the center will draw upon.

In preservation and conservation, there was a desire to continue the commitment to a "whole collections" philosophy. Instructors Karen Pavelka, a specialist in paper conservation, and Hal Erickson, whose specialty is materials science, were joined by Ellen Cunningham-Kruppa, a leader in the preservation program of the general libraries and a principal in the digital library of UT-Austin. In the spring of 2001, noted book conservator, Consuela "Chela" Metzger, will join the faculty. These professionals will strengthen our preservation studies program and the preservation components of the Center.

\section{Looking Ahead}

The next step is to find projects that will stimulate and foster interdisciplinary research. Joint ventures are being explored with a private corporation that looks at moving-image issues in archiving, preserving, indexing, and abstracting materials from Russia, Eastern Europe, and Latin America. Significant research related to iron gall ink in terms of both conservation and historical objects is ongoing. There is interest from many camps in the de la Peña manuscript project, which entails expertise in paper, ink, handwriting, forgery techniques in nineteenth-century documents, and historical sleuthing. ${ }^{1}$ 
The CCR hopes to support an electronic publication, host conferences and seminars, and generally serve as a stimulus for research and the exchange of ideas among curators, librarians, archivists, conservators, and anyone interested in historical objects.

\section{Conclusion}

The Center for the Cultural Record was established to draw on the common foci of the fields of archival and records enterprise, preservation and conservation, and museum studies. Initial issues that present pressing challenges relate to managing the source original in a digital environment; managing digital representations and using them to expand meaning and understanding of the source original (especially when the source original is born digital); and creating, stimulating, and enhancing the educational/informational function of documentary objects.

Certainly, there is much more to study and interested constituencies are encouraged to take an active role in guiding the direction of the CCR. www.cah.utexas.edu/exhibits/Pena/pena.html for more information. 